Article

\title{
Evaluation of the Geometallurgical Indexes for Comminution Properties at Sarcheshmeh Porphyry Copper Mine
}

\author{
Saiwan Mohammadi ${ }^{1}$, Bahram Rezai ${ }^{2, *}$,Aliakbar Abdollahzadeh ${ }^{3}$, Sayed Mojtaba Mortazavi ${ }^{4}$ \\ ${ }^{1 *}$ Department of Mining and Metallurgy Engineering, Amirkabir University of technology (Tehran \\ Polytechnic), Tehran, Iran; saiwan.mohammadi@yahoo.com; \\ ${ }^{2}$ Department of Mining and Metallurgy Engineering, Amirkabir University of technology (Tehran \\ Polytechnic), Tehran, Iran; rezai@aut.ac.ir ,Tel:+98-918-8775892; \\ ${ }^{3}$ Department of Mining Engineering, Faculty of Engineering, University of Kashan , Kashan, Iran; \\ abdzad@aut.ac.ir \\ ${ }^{4}$ Mineralogist Expert, Sarcheshmeh Copper Mine; mortazavi221@gmail.com
}

\begin{abstract}
Geometallurgy has become an important toll to predict the process behavior of the ores, and to decrease the production risks cause by variability of geological settings. In this paper geometallurgical index for grinding properties of the ore has investigated. In a comprehensive research at Sarcheshmeh porphyry copper mine, geological features, what were supposed to affect the main process responses including product's grade-recovery, and plant's throughput, were subjected to investigate as the possible geometallurgical indexes. The rock breakage variability, in terms of a ball mill grinding circuit and its effects on the plant throughput and energy consumption are presented. Ninety samples were collected based on geological features including lithology, hydrothermal alteration, and geological structures. The samples were characterized using $\mathrm{XRD}, \mathrm{XRF}$, and electron and optical microscopy. A simulated test method for Bond ball mill work index (BWI) was used to perform the comminution test. The results showed BWI values vary from $5.67 \mathrm{kWh} / \mathrm{t}$ to $20.21 \mathrm{kWh} / \mathrm{t}$. Examination of the possible correlations between BWI and the geological features showed that the key geological feature related to comminution variability is lithology. In addition, the hydrothermal alteration would be an effective parameter in the period that the plant is fed with a single lithology.
\end{abstract}

Keywords: geometallurgy, geometallurgical index, ore variability, comminution, Bond work index, Sarcheshmeh 


\section{Introduction}

Today, the mining industry faces significant challenges brought by technical and economic issues. Modern mining requires the exploitation of lower grade and more mineralogically complex, heterogeneous orebodies to satisfy the growing demands of industry[1]. In addition to the multiple processing difficulties impose by such ores, deep mining, environmental and social issues have become critical challenges towards the minerals industry's sustainable development.

In the mineral processing industry new trends have been focused on increasing efficiency along with optimization of energy consumption, with regard to product's grade and recovery, and plant's throughput. In recent years one of the most important attempts toward a sustainable mining activity has been focusing on creating a collective mine-to-mill or mine-to-market paradigm. Geometallurgy is the selected expression for the paradigm that tries to predict process performance of an ore in the plant, also the tailings in the dam through the integration of geology, mining, and processing parameters. Moreover, it has been proposed that market requirements could be considered in such a template. Potentially key outcomes of improved geometallurgical knowledge are enhanced forecasting, increased certainty, technical risk reduction, improved economic optimization of mineral production and sustainable mine development[2-5].

Geometallurgy could be divided into geometallurgical modelling, in case of technical investigations, and geometallurgical planning, from a management point of view. Geometallurgical modelling is the subjects those have been studied as 3D spatial modelling[6-9], geometallurgical tests[10-12], and integrated mineralogical approaches[13-15]. On the other hand, geometallurgical planning is mostly carried out based on a combination of the markets requirement and prediction, and the technical characteristics of a mining operation.

In this paper a novel geometallurgical modelling, in terms of geometallurgical index for the ball mill grinding process is presented at Sarcheshmeh porphyry copper mine. In the mineral processing, the term 'comminution' includes the following units operations: crushers, grinding mills (tumbling mills and stirred mills), and sizing processes[16]. Comminution is accountable for the most proportion of a mineral processing plant's capital and operation cost. Cohen estimated that up to $70 \%$ of total plant power draw is consumed by comminution[17]. Grinding, as the last stage of the comminution process, is the most energy-consumer operation in a mineral processing plant that can account for more than $50 \%$ of the operating cost[10].

\section{Ore body description}

Porphyry copper deposits are well known as the world's primary source of copper. Also, most of them contain important sources of molybdenum and gold[18, 19]. Sarcheshmeh Cu-Mo-Au mine is located $65 \mathrm{~km}$ southwest of Rafsanjan city, Kerman province, southeastern Iran. This porphyry deposit is occurred along with more than 50 porphyry and vein-style deposits and prospects in an elongated NW-SE trending Tertiary volcano-plutonic belt of approximately $450 \mathrm{~km}$ length and an average width of $80 \mathrm{~km}$ (Dehaj-Sarduiyeh belt); as the southern segment of Urumieh-Dokhtar magmatic arc[20]. The deposit is well known as a typical copper porphyry deposit in respect of alteration types, mineralization style, ore grade and size, tectonic setting, and rock features[21-23].

The Sarcheshmeh orebody is centered on a granodiorite-quartz monzonite porphyry stock which is locally called Sarcheshmeh porphyry (SP). The core area of the principle stock appears to have been intruded by a fine-grained granodiorite intra-mineralization, which is called late fine grained porphyry (LF). A series of intra to post mineralization dikes (i.e. hornblende porphyry, feldspar porphyry, and biotite porphyry) with variable compositions cut the porphyries and andesitic wall rocks[24]. The andesite wall rock, with lower content of copper, has surrounded the mineralized zone. Hydrothermal alterations and the mineralization at Sarcheshmeh are centered on the stock. The early hydrothermal alteration was dominantly potassic and propylitic, and was followed later by phyllic, silicic and argillic alteration[22]. Figure 1 shows the main rock types and Figure 2 shows the hypogene alterations. 

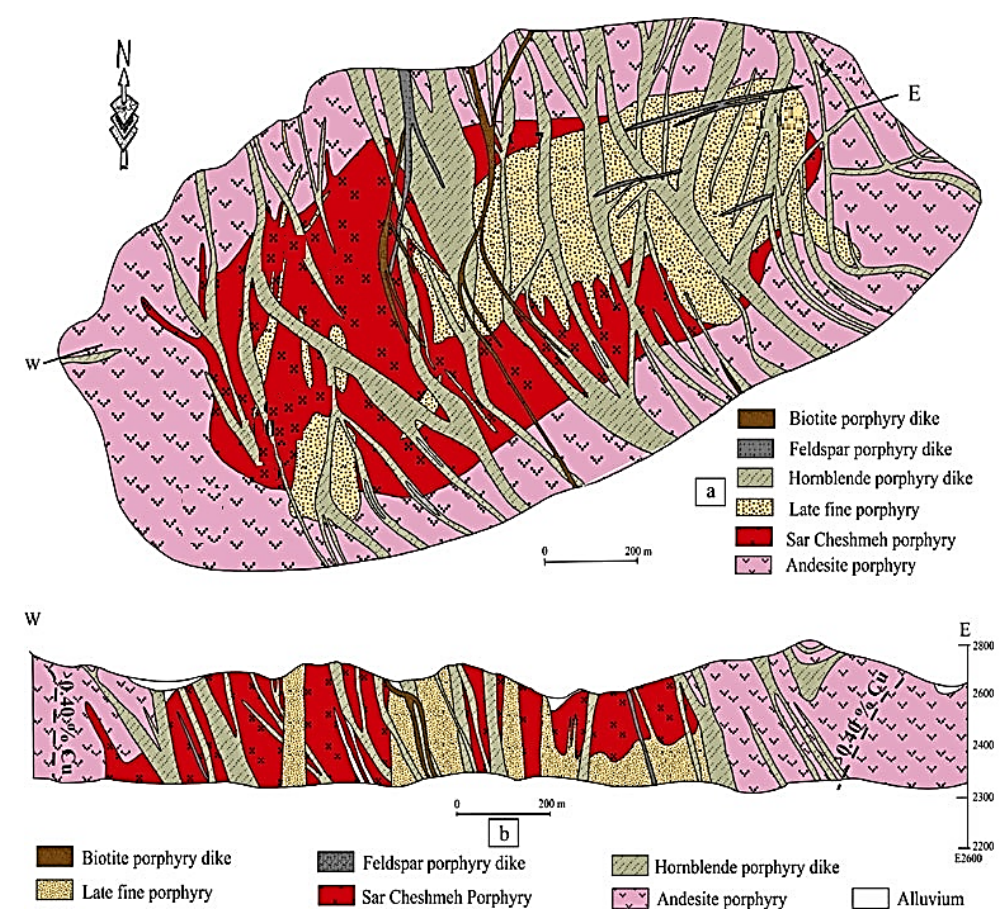

Figure 1. (a) map showing distribution of the main rock types in the Sarcheshmeh deposit within $0.40 \%$ $\mathrm{Cu}$ cutoff at 2,400 m elevation. (b) East-west cross-section of the Sarcheshmeh deposit[24, 25].

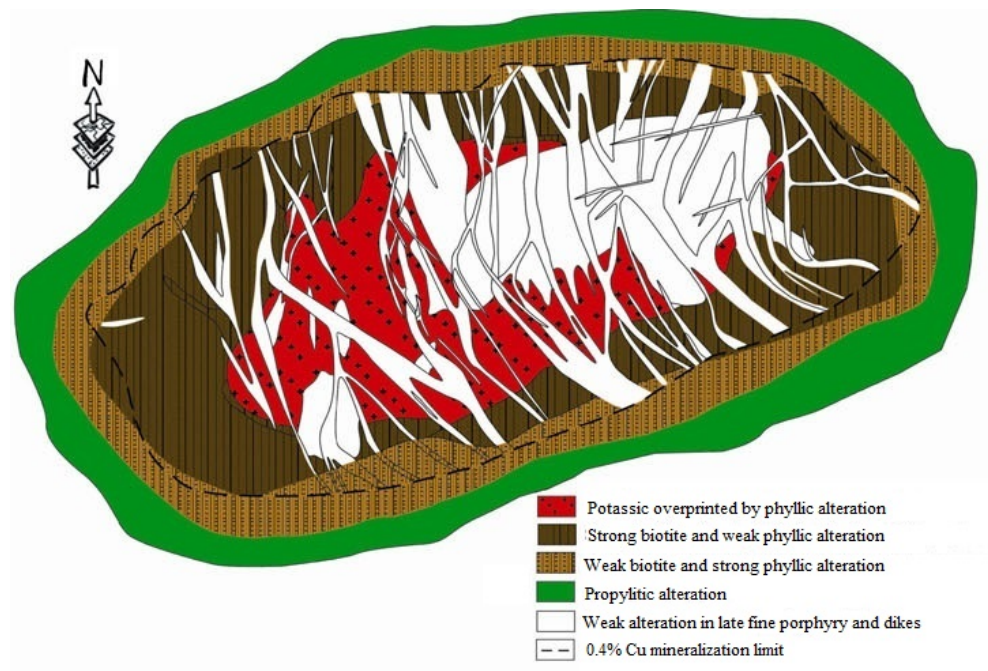

Figure 2. Hypogene alteration pattern in the Sarcheshmeh deposit within the $0.40 \%$ Cu cutoff at 2,400 m elevation[24].

\section{Materials and Methods}

In order to apply a geometallurgical assessment several methods have been tried to gain the knowledge, and create a predictive capability. Based on a comprehensive survey three different geometallurgical approaches have been identified[26]: traditional, proxies, and mineralogical. In the traditional approach chemical assays form the basis of the geometallurgy, and the metallurgical response is calculated from the chemical composition of the ore. The traditional approach is usable in the deposits with low geological variability. The proxies approach uses geometallurgical tests to characterize the metallurgical behavior of ore in processing stages. Examples of geometallurgical tests are Davis tube[27] and Minnovex crusher index test[28]. The mineralogical approach refers to the program where geometallurgical model (i.e. deposit and process model) is built largely based on 
mineralogy. Often this means that accurate information on modal mineralogy is needed for the whole ore body[29].

In the present work new methodology was used based on a combination of the proxies and mineralogical approaches, by employing the geological information, mineralogical characterization, and geometallurgical tests (Figure 3). In this method, after specifying the key ore forming parameters by geological surveying, the samples would be taken for geometallurgical tests (GT). Based on the target metallurgical response, some quantitative and/or qualitative set points are defined. If the results lead to a normal process response, a regular geometallurgical index would be introduced for that treated domain. If out of line results happen, detailed process mineralogy should be carried out and the GTs repeat with a new condition, or new GTs should be applied. The results of repeated/new GTs wouldn't necessarily lead to a better result, but could confirm the primary results. Based on the results some geometallurgical indexes are defined, where they are consist of one geological parameter or maybe a combination of parameters would be included.

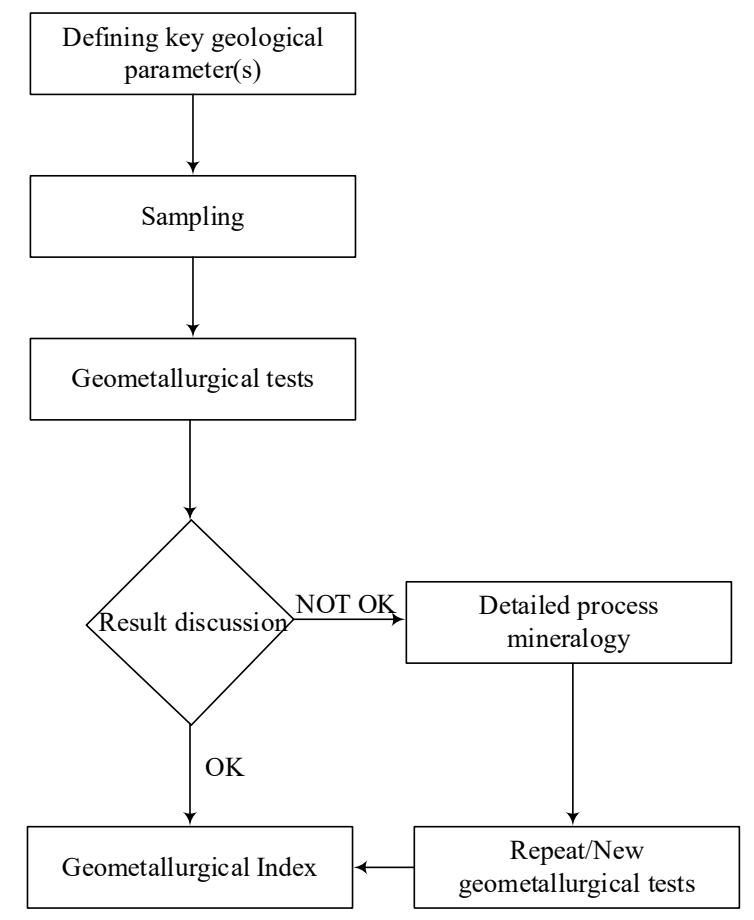

Figure 3. Schematic pathway for implementing geometallurgy

In this work sampling was performed, based on specified key geological parameters. The Bond ball mill work test (BWI) was selected as the geometallurgical comminution test (GCT). For the samples which the results were out of norm, the detailed process mineralogical studies were performed. Finally, the geometallurgical indexes were identified based on the results of geometallurgical tests and mineralogical characterization.

\subsection{Key ore-forming parameters at Sarcheshmeh}

In order to find out the key ore-forming parameters related to comminution properties at Sarcheshmeh deposit, all the geological information, including lithology, alteration, mineralization zones, and structural control parameters were studied as potentially GIs. The mineralization zones are divided to oxidation, supergene enrichment and hypogene. Currently, at Sarcheshmeh, extraction of oxidation zone and most of supergene zone have been finished and most of mineralization is hypogene form and locally remained supergene. Therefore, mineralization was removed as a key potentially GI factor. As well as, structural control was limited to the texture of rocks, therefor it was not selected as an independent geological feature. As a result, lithology and alteration were selected 
as the key geological parameters affecting the hardness specification of the ores, and hence the possible GIs.

\subsection{Sampling}

The number of samples, the amount of required sample, and the spatial location of samples in the mine block are three under discussion issues in geometallurgy[30-32]. In addition to budget restriction, time consuming GTs are the major limitation for choosing a sampling paradigm that covers all variations. However some works tries to use a broad number of samples for geometallurgical modelling, but these works are not a result of the common GTs, and most of them have used the reserve estimation parameters, such as grades, RQD, and semi quantitative mineralogical and geological information[33]. For this reason some modelling and simulation tools, such as geostatistics and principle component analysis (PCA), as data driving approaches, have been used limitedly[34]. Therefore, in this paper finding GIs, based on a limited number of samples, was selected as the road map for mapping the hardness variability.

Hand-picked and drill core samples were collected at 17 different zones within the mine block. Each sample was about $20 \mathrm{~kg}$ for hand-picked and one meter half drill core for the underground samples(Table 1). The lithologys were Sarcheshmeh porphyry (SP), granodiorite (GR), late fine porphyry (LF), andesite (AN), and dikes (DI). The lithology of first three were granodiorite, monzogranite, and quartz monzonite. Phyllic and potassic alteration were the main alterations in the mineralized zone, which based on the degree of alteration, phyllic was consists of sericite-quartz (SQ), quartz-sericite (QS), and silicified (SI). Also, potassic alteration was divided into biotite (BI) and potassic $(\mathrm{PO})$ alterations.

Table 1. The number of samples were taken in different lithologys and alterations

\begin{tabular}{|c|c|c|c|c|c|c|}
\hline \multirow{2}{*}{ Alteration } & \multicolumn{5}{|c|}{ lithology } \\
\cline { 2 - 7 } & AN & SP & GR & LF & DI \\
\hline \multirow{3}{*}{ Phyllic } & SQ & 3 & 5 & 3 & 0 & 0 \\
\cline { 2 - 7 } & QS & 9 & 11 & 6 & 8 & 3 \\
\cline { 2 - 7 } & SI & 6 & 3 & 4 & 5 & 2 \\
\hline \multirow{3}{*}{ Potassic } & BI & 4 & 0 & 0 & 0 & 0 \\
\cline { 2 - 7 } & PO & 0 & 5 & 4 & 9 & 0 \\
\hline
\end{tabular}

\subsection{Characterization study}

Characterization studies including chemical and mineralogical examinations were carried out. Each sample was visually observed for macro structures, texture, lithology, alteration and rough mineralogy. Also, the samples were characterized by chemical composition and qualitative and quantitative mineralogical examinations. $\mathrm{XRF}, \mathrm{XRD}$, petrographic microscopy, scanning electron microscopy (SEM), and mineral liberation analysis (MLA) were used on fresh and ground samples. Lithology determination, modal mineralogy, texture, associations, grain size, micro structures, and alteration were investigated in the characterization studies. By a combination of chemical analysis, semi-quantitative $\mathrm{XRD}$, and the modal analysis technique, the major minerals which accounted for more than $90 \%$ to $98 \%$ of the mineralogical composition were identified. Also, MLA was used on five ground samples to calibrate the semi-quantitative XRD in order to identifying the exact amount of major minerals, because XRD is more available analytical equipment and easy to conduct. Petrographic microscopy and SEM were practiced to pick out the ore texture specifications, including particle size, shape of minerals, distribution of minerals and minerals association. Also, alterations were classified by using analysis of major elements and mineralogical compositions. 


\subsection{Geometallurgical Comminution tests}

Geometallurgical tests (GT) are common metallurgical examinations, such as comminution, flotation, gravity, and magnetic tests. They are used to characterize any potentially variation in the metallurgical properties, quantitatively. However, in geometallurgy exact figures are not as important as domains. In geometallurgy, a domain is an exclusive classification of ore by a common property or set of properties[4]. Therefore, precision is not considered as much important as accuracy. For this reason, using the alternative simplified tests are possible for geometallurgical tests.

The resistance of ore samples to breakage is measured through crushability and grindability testing. Geometallurgical comminution tests (GCT) are used to predict the throughput of a mineral processing plant in a variable ore deposit. According to[12], a proper GCT should fulfill the following requirements: (1) the test is relatively simple, (2) the test should be repeatable and not person dependent, (3) the test is easy to conduct, (4) the test is fast and inexpensive, (5) the required sample size is small, (6) tests should give values for both crushability and grindability, (7) the results of the test can be used in modeling and simulation, and (8) it should be possible to extend the test by including mineral liberation information.

\subsubsection{Bond Ball Mill Work Index}

Bond ball mill work index (BWI) was first established by Bond[35, 36] which is still the most used approach in the design and analysis of comminution circuits[37]. The bond test applies a standardized ball mill of $305 \mathrm{~mm}$, both in diameter and length. The required sample is around $10 \mathrm{~kg}$ with particle size of finer than $3.35 \mathrm{~mm}$. The test is conducted in a dry locked-cycle, until the circulation load reaches to $250 \%$. The test often needs 7 to 10 cycles to meet the defined criteria. The BBWI $[\mathrm{kWh} / \mathrm{t}]$ is then calculated by using the Bond's empirical Equation 1

$$
\begin{aligned}
& W_{i}=1.1 \times \frac{4.45}{P^{0.23} \cdot G^{0.82} \cdot\left(\frac{1}{\sqrt{p_{80}}}-\frac{1}{\sqrt{f_{80}}}\right)} \\
& W_{i}: \text { Bond ball mill work index, }(\mathrm{kWh} / \mathrm{t}) \\
& P: \text { target screen size, }(\mu \mathrm{m}) \\
& G \text { : Mass of product per number of revolutions passing } P \\
& p_{80 \text { and }} f_{80}: 80 \% \text { passing size of product and feed respectively, }(\mu \mathrm{m})
\end{aligned}
$$

(Equation 1)

Because of rather time consuming and the significant sample requirement, several suggestions have been made over years to modify the Bond test. Nematollahi (1994) used a scaled down test with a coefficient of two-thirds of the standard Bond ball mill that both the diameter and length are 200 $\mathrm{mm}$ [38]. The test is operated at the same critical speed as the Bond ball mill runs. The mill is charged with 85 steel balls weighing $5.9 \mathrm{~kg}$, ranges from 16 to $38 \mathrm{~mm}$. The ore is packed to $207 \mathrm{~cm}^{3}$ volume instead of $700 \mathrm{~cm}^{3}$ that is standard of Bond test. The test is conducted to produce a circulating load of $250 \%$. After reaching equilibrium, the grindability of the last three cycles are averaged. Equation2 is used to calculate the ball mill work index.

$$
W_{i}=\frac{11.76}{P^{0.23} \cdot G^{0.75} \cdot\left(\frac{1}{\sqrt{p_{80}}}-\frac{1}{\sqrt{f_{80}}}\right)}
$$

(Equation 2)

Where $P, G, p_{80}$ and $f_{80}$ are the same with Equation 3.

The results obtained by Nematollahi method have been compared with the bond ball mill test, and the results show a maximum relative error of $5 \%$. 
Therefore, because of lower sample requirement and more rapid procedure, Nematollahi's standard ball mill was used in order to calculate the equivalent BWI. Also, the test was repeated on 10 samples for calculation of standard deviation.

\section{Results and Discussion}

\subsection{Geological and mineralogical features}

Based on the geological investigation in the mineralized zone, the key geological ore forming parameters of the Sarcheshmeh porphyry deposit related to comminution properties were divided into lithology and hydrothermal alteration. Mineralized zone at Sarcheshmeh deposit is consist of volcanic, intrude sub-volcanic, and intrusive rocks. The volcanic wall rock with low grade mineralization is a fine-grained andesite (AN) porphyries. SP is an early mineralization granodiorite to quartz monzonite stock which is intruded into the volcanic andesite rocks. The texture in the SP is a combination of porphyritic, which generally consists of plagioclase and quartz phenocrysts in a fine siliceous matrix, and granular texture. LF is a sub-volcanic to intrusive post mineralization quartzmonzonite and granodiorite rock with a fine grain texture. The dikes (DI) have a wide range of volcanic and intrusive lithologies which they are divided into hornblende porphyry, feldspar porphyry, and biotite porphyry. GR is the ore shell and the outer layer of mineralized zone, where low copper mineralization has occurred.

Phyllic and potassic alterations were predominant in the mineralized zones. Based on the degree of alteration, the phyllic alteration was divided into three stages including sericite-quartz (SQ), quartz-sericite (QS), and silicified (SI). Also, potassic alteration was divided into biotite (BI) and potassic $(\mathrm{PO})$ alteration, too.

The predominant minerals in the samples were quartz, alkali-feldspar, plagioclase, and clay minerals including chlorite, kaolinite, illite, montmorillonite, and dickite. Disseminated chalcopyrite, pyrite, chalcocite, and minor molybdenite were the sulfide minerals.

Major geological and mineralogical characteristics related to comminution properties are shown in the Figure 4 . Porphyritic texture with phenocryst minerals in a fine grained matrix, heterogeneous altered minerals, veinlets, and minerals size and shape were identified as the reasons for different comminution behavior. Phaneritic textured rocks comprised of large particles in granodiorite rocks verses aphanitic and porphyritic textures, with small particles, in andesitic rocks were predominant primary textures ((Figure $44 \mathrm{~A}$ and B). Secondary textures are mostly the results of alterations and they were identified as altered fine grain minerals, specially sericite and biotite, and clay minerals (figure $4 \mathrm{C}$ ). Veinlets were also filled by secondary minerals (Figure $4 \mathrm{D}$ ). The most notable texture in SP was a combination of large phenocryst and xenolith particles in a matrix of fine particles, representing the intrusion in the primary volcanic wall rock. 


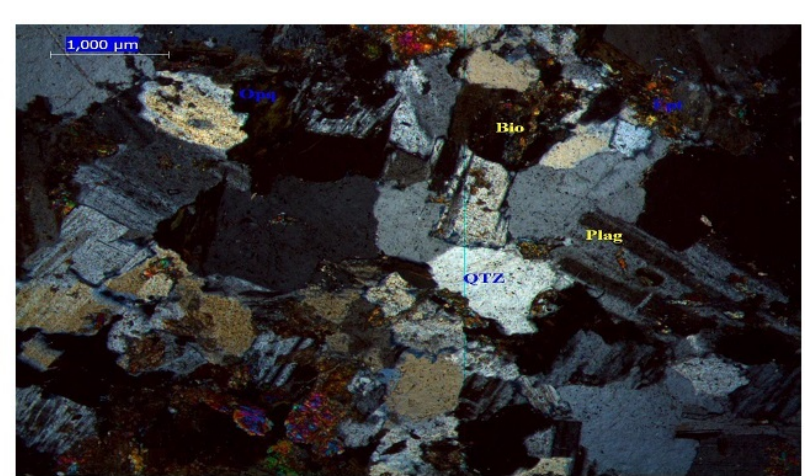

A

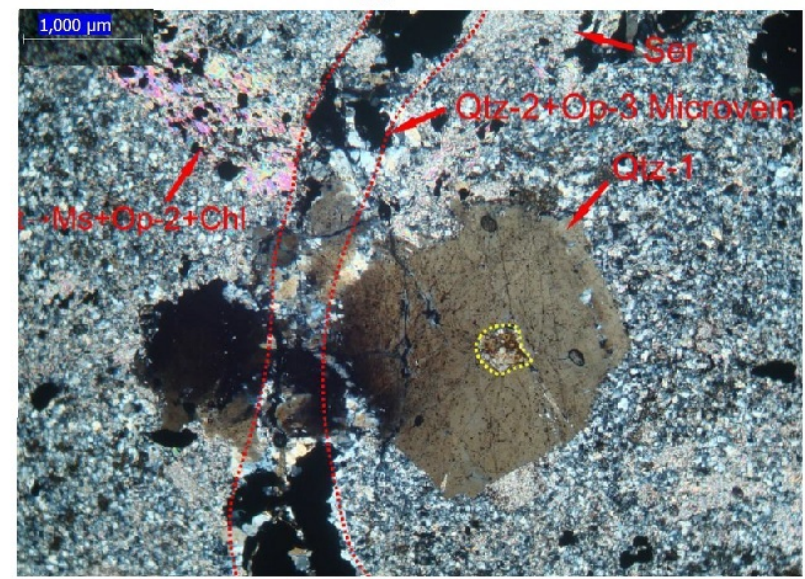

$\mathrm{C}$

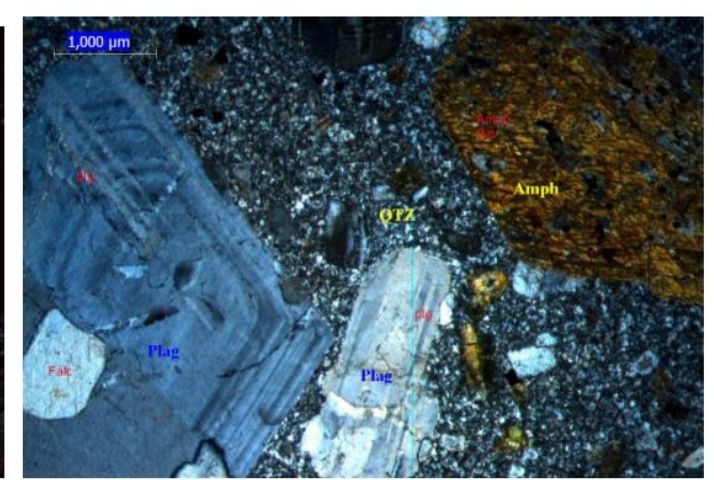

$\mathrm{B}$

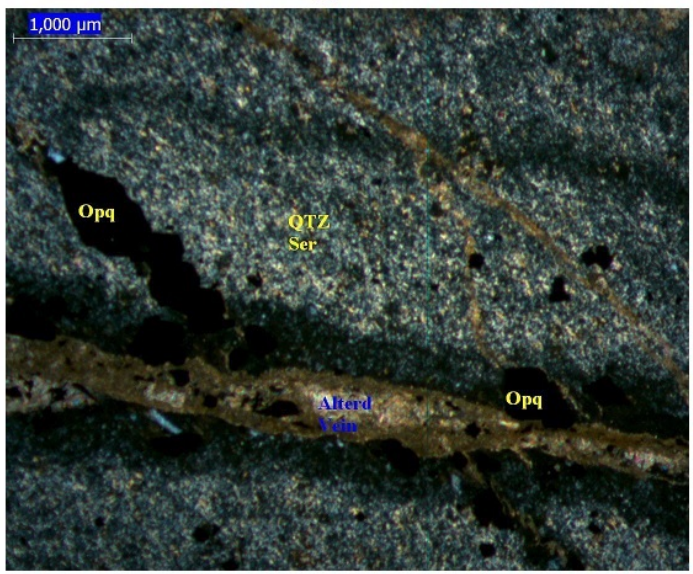

$\mathrm{D}$

Figure 4. Major textures at Sarcheshmeh. A primary preserved texture. B, C and D: secondary altered textures. plagioclase altered into sericite with a fine grain quartz and filled veinlet

\subsection{Ball mill work index (BWI)}

The calculated values of BWI indicated a wide range of required power draw. The results were ranked according to their resistance to a comminution process experienced inside a ball mill from the weakest to hardest. Based on the BWI values, the samples were classified into soft (less than $10 \mathrm{kWh} / \mathrm{t}$ ), medium (10 -15 kWh/t), and hard (more than $15 \mathrm{kWh} / \mathrm{t})$. Based on the mentioned classification, the results indicated 22 percent of samples are soft, 58 percent of samples are medium, and 20 percent of samples are hard to grind.

\subsubsection{BWI variability and lithology}

The results of BWI test on the samples is shown in Table 2. The minimum value of BWI is 5.67 $\mathrm{kWh} / \mathrm{t}$, belongs to a sample located in SP, and the maximum value is $20.21 \mathrm{kWh} / \mathrm{t}$, belongs to a sample located in DI lithotype. The average values of BWI for SP, AN, GR, DI, LF were 8.85, 12.59, 14.07, 14.86 , and 15.31, respectively. The simple average of BWI, including all samples, is $13.06 \mathrm{kWh} / \mathrm{t}$, while the weighted average of BWI, that is the real required power draw for ball mill circuit, would be a function of the GI, by considering the mine's block model.

Table 2. the results of BWI tests on different lithologies

\begin{tabular}{ccccccc}
\hline & \multicolumn{7}{c}{ Lithology } \\
\hline & \multicolumn{7}{c}{ SP } & AN & GR & DI & LF \\
\cline { 2 - 7 } BWI & Min-max & $5.67-9.98$ & $8.63-16.29$ & $11.68-17.79$ & $11.78-20.21$ & $13.14-16.75$ \\
\cline { 2 - 7 }$(\mathbf{k W h} / \mathbf{t})$ & Average & 8.85 & 12.59 & 14.07 & 14.86 & 15.31 \\
\hline
\end{tabular}


The results of BWI indicate, despite a common lithology in SP, LF, GR there are significant differences of the BWI, and consequently the ball mill power draw. The difference in the breakage properties of SP and LF lithologies, where they are close to each other at the mine pit, is a result of different texture, different degrees of alteration, and different initial condition of formation. At the micro scale, LF has a fine grain and granular texture (Figure $5 \mathrm{~A}$ ). The dimension of minerals is less than $1 \mathrm{~mm}$, and mostly micronize. Also, in a macro scale, LF is a post mineralized stock, with lesser weathering and alteration. The number of silicic stockworks in the LF is fewer than SP. The predominant alteration in the LF is phyllic alteration with the high content of fine sericite. At the other hand, SP has a coarser particles with porphyritic and granular texture (Figure 5 B). The predominant alteration is QS with high content of quartz and sericite. The structural controls in the SP are more than LF, and most of the lower BWI was observed in the shear zones. The veinlets which they are filled with secondary minerals are could be considered as another reason for a low grinding resistance (Figure $4 \mathrm{D})$.

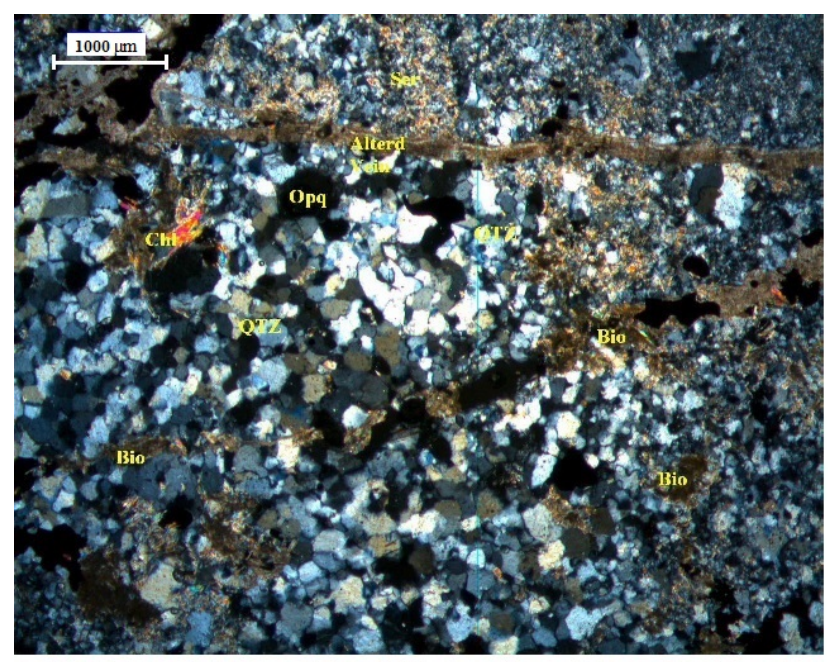

A

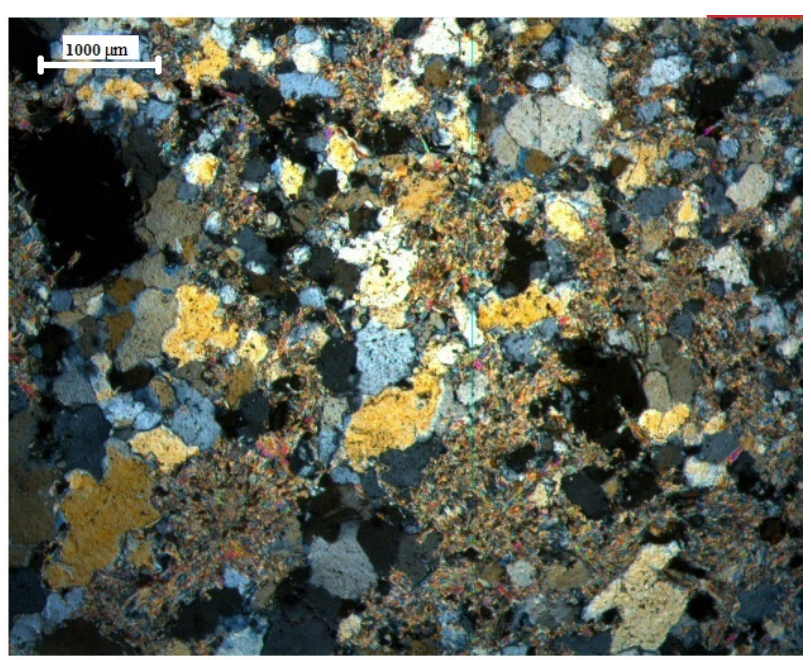

B

Figure 5. A: LF with fine particles and weak alteration, B: SP with coarser particle and strong alteration

\subsubsection{BWI variability and alterations}

The effect of alteration on the BWI was found to be different and sometimes contradictory. The lithologies with phyllic alteration have a wide range of BWI, from soft to hard. The integration of BWI and characterization studies indicate that the resistance to grinding increases in the phyllic alteration by increasing the degree of alteration. As the process of phyllic alteration increases, the plagioclase feldspars in the original rock are replaced by alteration minerals, which sericite and quartz content increase relative to the original amount[19]. Sericitisation is an acidic alteration that products white mica, mostly thin muscovite, calls sericite with a sericitic texture. If the hydrothermal alteration continues then ultimately the original minerals are completely replaced by quartz in a silicified form. Silicification was seen at Sarcheshmeh as quartz veins filling and stockworks. Both sericitisation and silicification cause increasing the BWI due to generated fine and flake particles.

The samples with potassic alteration were shown to have a medium to hard comminution properties. The average BWI was $15.5 \mathrm{kWh} / \mathrm{t}$. The samples with potassic alteration in the SP had the minimum and in the LF had the maximum BWI. Unlike the phyllic alteration, degree of alteration in the potassic alteration had a reverse effect on the BWI. In a unified lithotype with potassic alteration, the enhancement of the alteration process, decreased the BWI. 


\subsubsection{BWI variability and mineralogical composition}

Without considering other parameters, such as lithology, alteration, and structures, the modal mineralogy was used to investigate the correlation between mineralogical composition and BWI. In 15 samples major minerals, which accounted for $90 \%$ to $98 \%$ of the mineralogical composition, including quartz, orthoclase, plagioclase, chalcopyrite, clay minerals, sericite, and pyrite were used to create the modal mineralogy. The results in Figure 6 suggest that it is not possible to use the minerals content to predict the BWI, separately. The minimum BWI in the figure 6 belongs to a SP lithology with quartz-sericite alteration. At the other hand, the highest BWI belongs to a DI with the same alteration.

quartz $\square$ orthoclase $\square$ plagioclase $\square$ chalcopyrite $\square$ clay minerals $\square$ sericite $\square$ pyrite

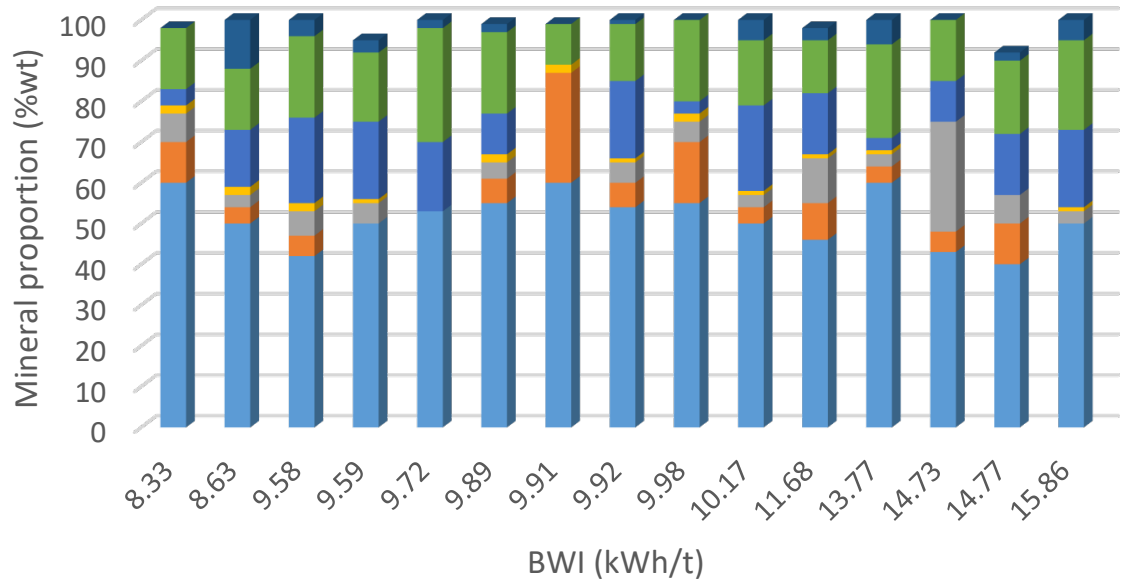

Figure 6. The correlation between modal mineralogy and BWI

Figure 7 shows quartz content verse BWI. The content of quartz in the softest and hardest samples were $60 \%$ and $50 \%$, respectively. The modal mineralogy shows the real content of quartz, without considering the primary quartz in the original rock and the secondary quartz that has generated during the alteration processes. For this reason, a specified lithology could hold different amount of a mineral. Secondary minerals, such as quartz were observable in the microscopic studies as fine grain, filled veinlet, and stockworks.

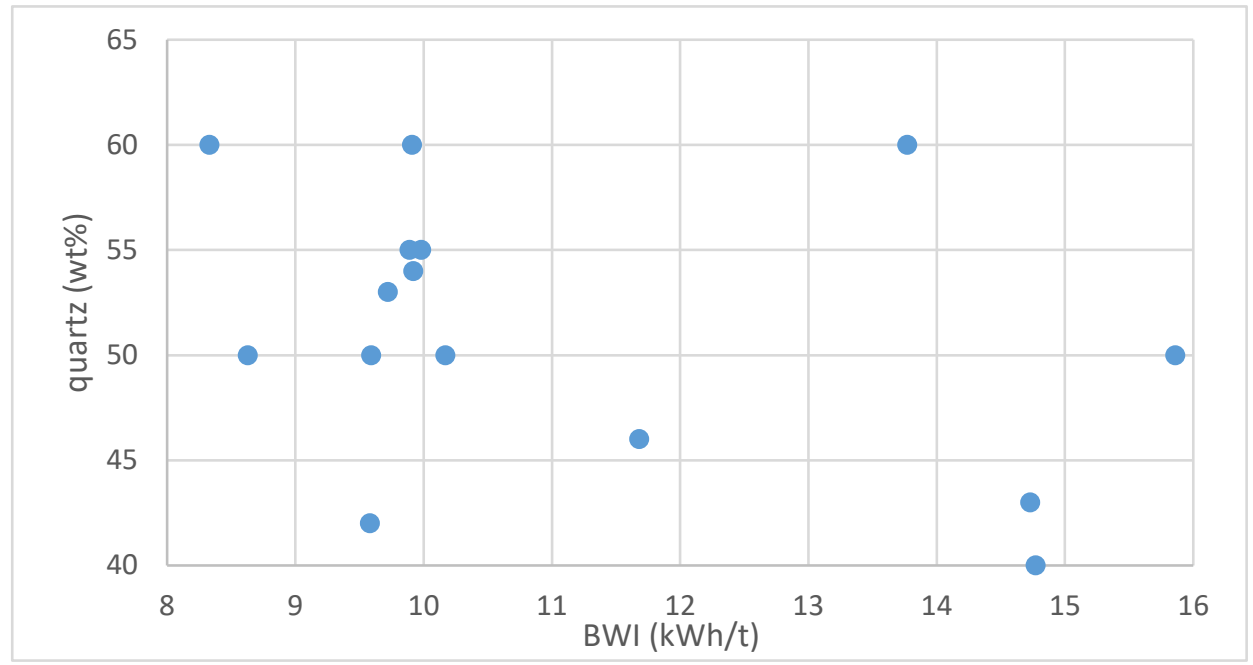

Figure 7. The correlation between quartz content and BWI 
Other mineral content, or a combination of minerals such as clays, were subjected to investigate any possible relation with BWI. Also, the total amount of quartz, plagioclase, and orthoclase minerals (QAP), as the common constituent minerals of igneous rocks, were used to predict the BWI. At the late case, the difficulty that was imposed by alteration minerals, did not let to correlate the BWI and mentioned mixture of minerals. For the clays mineral, the results shows in a specific lithotype, increasing an alteration that leads to a high content of clay minerals would increase the BWI, otherwise it was not possible to find a certain correlation. Also, the examination of physical property shows that it is expected that the comminution process would be faced with lower efficiency in a real operation due to the variations in the physical properties of pulp with the clay minerals.

\section{Conclusions}

This paper has provided a comprehensive new methodology to perform a geometallurgical program for defining geometallurgical indexes in a ball mill comminution process. The most important issues and the obtained results are:

- Smart sampling by predicting the key factors on the comminution properties.

- Geological features those selected as the key factors were rock types, alterations, geological structures and ore texture

- In Sarcheshmeh porphyry deposit lithology was shown to be the most important key factor on the ball mill comminution process.

- It can be concluded that if the mineralization occurs in a porphyry deposit with a single rock type, the alteration defines the hardness variability

- $\quad$ No systematic relation was observed between mineral composition and BWI

\section{References}

1. Voigt, M., et al., Developing a 3D mineral texture quantification method of drill core for geometallurgy. Journal of the Southern African Institute of Mining and Metallurgy, 2019. 119(4): p. 347-353.

2. Ashley, K. and M. Callow, Ore variability: Exercises in geometallurgy. Engineering and Mining Journal, 2000. 201(2): p. 24.

3. Bennett, C. and C. Lozano, The Architecture of the Geometallurgical Model. Proceedings Procemin, 2004: p. $1-8$.

4. David, D. The importance of geometallurgical analysis in plant study, design and operational phases. in Proceedings Ninth Mill Operators' Conference 2007. 2007.

5. Williams, S.R. and J. Richardson. Geometallurgical Mapping: A new approach that reduces technical risk. in Proceedings 36th Annual Meeting of the Canadian Mineral Processors. 2004.

6. $\quad$ Ehrig, K., Quantitative mineral mapping A building block for geometallurgy at Olympic Dam In: The First AusIMM International Geometallurgy Conference, 2011: p. 31.

7. Garrido, M., Sepulveda, E., Ortiz, J.M., Navarro, F., Townley, B A methodology for the simulation of synthetic geometallurgical block models of porphyry ore bodies. In: Procemin 14th International Mineral Processing Conference (PROCEMIN). 5th International Seminar on Geometallurgy (GEOMET). Santiago, Chile, 2018: p. 1-10.

8. Keeney, L., Walters, S.G, A methodology for geometallurgical mapping and orebody modelling. n: The First AusIMM International Geometallurgy Conference, 5-7 September 2011: p. 217-225.

9. Lishchuk, V., Lund, C., Lamberg, P. and Miroshnikova, E., Simulation of a mining value chain with a synthetic ore body model: Iron ore example. . Minerals, 2018: p. 536. 
10. Heiskari, H., et al., Development of a comminution test method for small ore samples. Minerals Engineering, 2019. 130: p. 5-11.

11. Hilden, M.M.a.P., M.S., A geometrical texture model for multi-mineral liberation prediction. Minerals Engineering, 2017: p. 25-35.

12. Mwanga, A., J. Rosenkranz, and P. Lamberg, Testing of ore comminution behavior in the geometallurgical context-A review. Minerals, 2015. 5(2): p. 276-297.

13. Koch, P.H., Lund, C. and Rosenkranz, J. . ., , pp., Automated drill core mineralogical characterization method for texture classification and modal mineralogy estimation for geometallurgy. Minerals Engineering, 2019. 136: p. 99-109.

14. Kuhar, L.L., Mcfarlane, A.J., Chapman, N.M., Meakin, R.L., Martin, R., Turner, N.L. Robinson, D.J. ， calibration and testing of a geometallurgical leaching protocol for determining copper mineralogical deportment. The Second AusIMM International Geometallurgy Conference, 2013.

15. Rincon, J., Gaydardzhiev, S. and Stamenov, L. , Coupling comminution indices and mineralogical features as an approach to a geometallurgical characterization of a copper ore. Minerals Engineering, 2019. 130: p. 57-66.

16. Napier-Munn, T.J., et al., Mineral comminution circuits: their operation and optimisation. 1996.

17. Cohen, H., Energy usage in mineral processing. Transactions of the Institution of Mining and Metallurgy, 1983. 92: p. 160-163.

18. Sillitoe, R.H., Porphyry copper systems. Economic geology, 2010. 105(1): p. 3-41.

19. Yildirim, B.G., et al., Development of an effective and practical Process Alteration Index (PAI) for predicting metallurgical responses of $C u$ porphyries. Minerals Engineering, 2014. 69: p. 91-96.

20. Boomeri, M., K. Nakashima, and D.R. Lentz, The Sarcheshmeh porphyry copper deposit, Kerman, Iran: A mineralogical analysis of the igneous rocks and alteration zones including halogen element systematics related to Cu mineralization processes. Ore Geology Reviews, 2010. 38(4): p. 367-381.

21. Boomeri, M., Nakashima, K. and Lentz, D.R. . s., The Sarcheshmeh porphyry copper deposit, Kerman, Iran: A mineralogical analysis of the igneous rocks and alteration zones including halogen element systematics related to Cu mineralization processe. Ore Geology Reviews, 2010. 38(4): p. 367-381.

22. Hezarkhani, A., Hydrothermal evolution of the Sar-Cheshmeh porphyry Cu-Mo deposit, Iran: evidence from fluid inclusions. Journal of Asian Earth Sciences, 2006. 28(4-6): p. 409-422.

23. Waterman, G.C. and R. Hamilton, The Sar Cheshmeh porphyry copper deposit. Economic Geology, 1975. 70(3): p. 568-576.

24. Shafiei, B. and J. Shahabpour, Geochemical aspects of molybdenum and precious metals distribution in the Sar Cheshmeh porphyry copper deposit, Iran. Mineralium Deposita, 2012. 47(5): p. 535-543.

25. Etminan, H., Le porphyre cuprifère de Sar Cheshmeh (Iran): rôle des phases fluides dans les mécanismes d'altération et de minéralisation. 1977, Fondation scientifique de la géologie et de ses applications.

26. Lishchuk, V., P. Lamberg, and C. Lund. Classification of geometallurgical programs based on approach and purpose. in SGA 2015: 24/08/2015-27/08/2015. 2015.

27. Niiranen, K. and A. Böhm, A systematic characterization of the orebody for mineral processing at Kirunavaara iron ore mine operated by LKAB in Kiruna, Northern Sweden. Impc 2012, 2012. 1039: p. 3855-3864.

28. Kosick, G., C. Bennett, and G. DOBBY-SGS, Managing Company Risk by Incorporating the Mine Resource Model into Design and Optimization of Mineral Processing Plants. TECHNICAL BULLETIN, 2002. 2002: p. 21.

29. Lamberg, P., et al. Building a geometallurgical model in iron ores using a mineralogical approach with liberation data. in Proceedings of the Second AusIMM International Geometallurgy Conference, Brisbane, Australia. 2013. 
30. Dominy, S.C., Connor, L.O., Xie, Y. . W.A., Sampling and testwork protocol development for geometallurgical characterization of a sheeted vein gold deposit. The Third AusIMM International Geometallurgy Conference, Perth, Australia, 2016: p. 97-112.

31. Lishchuk, V., Lamberg, P., Lund, C. , Evaluation of sampling in geometallurgical programs through synthetic deposit model. IMPC2016. Canadian Institute of Mining, Metallurgy and Petroleum, Quebec City, Canada, 2016a: p. 1-11.

32. Stewart, M., Coward, S., Vann, J. , Challenges of quality management in sampling and measurement of geometallurgical variables. Sampling Conference, 2010: p. 69-159.

33. Deutsch, J.L., et al., Spatial modeling of geometallurgical properties: techniques and a case study. Natural Resources Research, 2016. 25(2): p. 161-181.

34. Suriadi, S., et al., Isolating the impact of rock properties and operational settings on minerals processing performance: A data-driven approach. Minerals Engineering, 2018. 122: p. 53-66.

35. Bond, F.C.J.C.E., Crushing and grinding calculations Brit. 1961(8).

36. Bond, F.C.J.M.E., Third theory of comminution. 1952. 4: p. 484.

37. Mwanga, A., Rosenkranz, J. and Lamberg, P., Development and experimental validation of the Geometallurgical Comminution Test (GCT). Minerals Engineering, 2017. 108: p. 109-114.

38. Nematollahi, H.J.M.E., New size laboratory ball mill for Bond work index determination. 1994. 46(4): p. 352353. 